\title{
Volatile Organic Compounds in Crude Coconut and Petroleum Oils in Nigeria
}

\author{
Adedotun Adebowale, Tuan Phan \\ Department of Chemistry, Texas Southern University, Houston, Texas, USA \\ Email: phantd@tsu.edu
}

How to cite this paper: Adebowale, A. and Phan, T. (2017) Volatile Organic Compounds in Crude Coconut and Petroleum Oils in Nigeria. American Journal of Analytical Chemistry, 8, 371-379. https://doi.org/10.4236/ajac.2017.86028

Received: November 30, 2016

Accepted: June 9, 2017

Published: June 12, 2017

Copyright (C) 2017 by authors and Scientific Research Publishing Inc. This work is licensed under the Creative Commons Attribution International License (CC BY 4.0).

http://creativecommons.org/licenses/by/4.0/

(c) (i) Open Access

\begin{abstract}
Analysis of Volatile Organic Compounds (VOCs) in crude coconut and petroleum oils from Nigeria is reported. Using head-space gas chromatography with a flame ionization detector and mass spectrometer, 8 VOCs were found in crude coconut oil and 29 VOCs were identified in crude petroleum oil. Crude coconut oil contained two aromatic, two nitrogenated, and four oxygenated compounds. Alkane, alkene, alkyne, halogenated, and sulfur compounds were absent in crude coconut oil but not in crude petroleum oil. The same observation held true for naphthalene. Conversely, benzofuran was absent in crude petroleum oil but was present in crude coconut oil at a concentration of 1.38 part-per-billion (ppb). The most concentrated VOC in crude coconut oil was dodecanoic acid at $9.98 \mathrm{ppb}$ and that of crude petroleum oil was toluene at $12.61 \mathrm{ppb}$. Total VOC concentrations in crude coconut and petroleum oils are 20.49 and $87.46 \mathrm{ppb}$, respectively. These results are helpful in characterizing the chemical signature of Nigerian crude coconut oil for potential forensics use or in biofuel research.
\end{abstract}

\section{Keywords}

Coconut Oil, Petroleum Oil, VOCs, Gas Chromatography, Biofuel

\section{Introduction}

The potential use of coconut oil as a biofuel has prompted significant economic and environmental research in recent years. Biofuel is produced by transesterification of oil by reacting it with methanol in the presence of a catalyst such as $\mathrm{NaOH}$ to form methyl esters as biofuel and glycerin as a by-product [1] [2]. Burning of coconut oil releases less $\mathrm{CO}_{2}$ into the atmosphere as compared to petroleum oil [3]. Coconut oil is also a renewable resource. Even though the specific energy, viscosity, and cetane number are similar in coconut and petroleum 
oils, coconut oil has comparatively more physiochemical limitations related to relatively high viscosity, iodine concentrations, boiling point, and cloud point/ wax formation as well as the presence of residual water [4] [5] [6] [7] [8]. Nevertheless, coconut oil has the most suitable physical properties among all vegetable oils for biofuel generation. Table 1 compares some physical properties of coconut and petroleum oils. The extensive use of coconut in the production of biofuel may affect the diversity of the agroecosystem by shifting the farming interest to coconut potentially compromising the production of other crops and affecting the price of coconut [9].

Crude petroleum oil is a complex liquid hydrocarbon that occurs naturally, consisting hundreds of hydrocarbons with some sulfur, oxygen and nitrogen impurities. Its combustion contributes greatly to historically increasing atmospheric carbon dioxide $\left(\mathrm{CO}_{2}\right)$ concentrations, a factor in climate change. Some petrochemical oil combustion products are harmful to human [10] [11] [12] [13]. Leakage and spillage of petroleum oil during transportation can adversely affect the marine environment [14].

Volatile organic compounds (VOCs) vaporize easily at ambient temperatures. Tucker defined VOCs as a class of carbon-containing chemicals that participate in photochemical reactions in ambient air [15]. VOCs are also known to have boiling points of $\leq 100^{\circ} \mathrm{C}$ and/or vapor pressures $>1 \mathrm{mmHg}$ at $25^{\circ} \mathrm{C}$ [16]. VOCs are found in many products such as fuels, solvents, paints, adhesives, and refrigerants, and are abundant automobile engine exhaust [17]-[22]. Indeed, the presence of VOCs in the environment continues to be a major subject of public concern and active research. In light of the great impact of VOCs on human health and environment, the objective of this paper is to examine the types and concentrations of VOCs in crude coconut oil and compare them to those in crude petroleum oil. This will help characterize the chemical signature of crude coconut oil for potential forensics use or in biofuel research.

\section{Experimental Procedures}

\subsection{Samples and Reagents}

Crude coconut and petroleum oils were obtained from Department of Petroleum Engineering, University of Ibadan, Nigeria. These oils were collected around the city of Ibadan, Nigeria. A sample $(20 \mathrm{~g})$ of each oil was placed in individual headspace vials, which were subsequently sealed. NIST-traceable and certified

Table 1. Some physical properties of coconut and petroleum oils.

\begin{tabular}{ccc}
\hline Oil & Coconut & Petroleum \\
\hline Heating value $(\mathrm{MJ} / \mathrm{Kg})$ & 35.80 & 43.96 \\
Density $\left(\mathrm{Kg} / \mathrm{m}^{3}\right)$ & 915 & 828 \\
Viscocity $(\mathrm{Pa} \cdot \mathrm{s})$ & 0.03159 & 0.00361 \\
Surface tension $(\mathrm{N} / \mathrm{m})$ & 0.0348 & 0.0318 \\
\hline
\end{tabular}


standards were used to calibrate the GC/MS. All purchased reagents were analytical grade and used without further purification. Pure standards were purchased from Sigma-Aldrich (USA). Stock standard solutions for each of the analytes were prepared in a $100 \mathrm{mg} / 100 \mathrm{ml}$ of methanol. Ultra-high-purity grade helium was obtained from Air Liquide (USA). Helium was used as the carrier gas in the GC runs. Ultra-high-purity grade nitrogen was produced in the laboratory using nitrogen generator for use as make-up gas. Compressed air and hydrogen were purchased from Air Liquide.

\subsection{Gas Chromatography}

Sealed vials containing the oil samples were placed in a thermostat to drive the volatile components into the headspace for analysis. An aliquot of the vapor phase was introduced through a gas-tight syringe or the sample loop of a gas sampling valve into a GC. The GC was configured for: $500 \mu \mathrm{L}$ split/splitless injection at $200^{\circ} \mathrm{C}$, an initial oven temperature of $40^{\circ} \mathrm{C}$ for $5 \mathrm{~min}$, a final temperature ramp from $40^{\circ} \mathrm{C}$ to $235^{\circ} \mathrm{C}$ at $5^{\circ} \mathrm{C} \cdot \mathrm{min}^{-1}$, and a helium carrier gas velocity $1.25 \mathrm{~mL} / \mathrm{min}$. The MS was configured for a $0 \mathrm{~min}$ solvent delay, temperature of $280^{\circ} \mathrm{C}, 2200 \mathrm{EMV}$, and 45 to $450 \mathrm{MS}$ scan at $1.9 \mathrm{Scan} / \mathrm{s}$. Headspace-GC cycle time was set at $60 \mathrm{~min}$, and the injection time was set $1 \mathrm{~min}$. The oven temperature was held at $95^{\circ} \mathrm{C}$, the $\operatorname{Tr}$ line temperature was $150^{\circ} \mathrm{C}$, and the loop temperature was $100^{\circ} \mathrm{C}$. The loop EQ time was $0.05 \mathrm{~min}$, the loop fill time was 0.20 $\mathrm{min}$, the pressure time was $0.20 \mathrm{~min}$, and the vial EQ time was $15.0 \mathrm{~min}$.

Quantitative analysis of samples was performed using an Agilent 7890A gas chromatography equipped with a flame ionization detector and a DB5 capillary column $(25 \mathrm{~m} \times 0.25 \mathrm{~mm})$. Internal standards were used to calculate the concentrations of VOCs by the following equation [23]:

$$
U_{c}=Q_{i} *\left(B_{i} / B_{\text {ref }}\right) /\left(\left(B_{i} / B_{\text {ref }}\right)-\left(A_{i} / A_{\text {ref }}\right)\right)
$$

where $i$ and ref represent a VOC to be determined and the internal standard, respectively. Standards and actual samples were run using the same experimental conditions, and VOC retention times were compared. Internal standards are carefully selected so that their peaks are close to but completely separate from the peaks of $i . B_{i} / B_{\text {ref }}$ is the ratio of the peak areas of $i$ to the internal standard after being added to the sample being analyzed. $A_{i} / A_{\text {ref }}$ is the ratio of the peak areas of $i$ to the internal standard before it is added. $Q_{i}$ is defined as the amount of internal standard added in $\mu \mathrm{g}$, and $U_{c}$ is the calculated amount of the VOC in $\mu \mathrm{g}$. The relative response factors and recovery factors of $n$-alkane internal standards were also calculated. The relative response factors and recovery factors of the investigated VOCs were determined based on the internal standard with similar structures. Finally, concentrations of VOCs were then adjusted for their recoveries.

VOCs were identified by mass chromatography, using Agilent $780 \mathrm{~A}$ gas chromatograph equipped with a mass spectrometer. An attached auto sampler was used for the qualitative identification of VOCs. The GC used a $25 \mathrm{~m} \times 0.25$ 
mm i.d. $\times 0.25 \mu \mathrm{m}$ film thickness HP5 fused silica capillary column and liquid auto sampler. GC conditions were $1 \mathrm{~mL}$ split/splitless injection (injector temperature of $270^{\circ} \mathrm{C}$ ) at $60^{\circ} \mathrm{C}$, a splitless time of $60 \mathrm{~s}$, a $3 \mathrm{~min}$ hold, a temperature increase of $3^{\circ} \mathrm{C} \cdot \mathrm{min}^{-1}$ to $300^{\circ} \mathrm{C}$, and a helium carrier gas velocity $30 \mathrm{~cm} \cdot \mathrm{s}^{-1}$.

A minimum detection limit (MDL) of less than 500 parts per trillion (ppt) was determined. Five calibration points were used to establish linearity for the quantitative analysis of target compounds. The calibration was verified for each compound using the calculated Relative Response Percentage and the Correlation Coefficients value for linearity. Before any analysis was completed, a certification blank was run through the column to establish a baseline. During calibration and sample analysis, a blank was inserted between each sample to ensure that no carry-over or contamination occurred.

\section{Results}

A representative chromatogram is shown in Figure 1 for crude coconut oil. Mass spectra of the most abundant VOC in coconut oil (dodecanoic acid) and petroleum oil (toluene) are shown in Figure 2. The data are referenced to the mass spectral databases of US-NIST/EPA/NIH mass spectral library-NIST98.

VOCs found in the crude petroleum oil samples are listed in Table 2. Alkane compounds identified in crude petroleum oil were 2-methylbicyclo[3.2.1] octane, 5-ethyl-2,2,3-trimethyl heptane, decane, dodecane, octane, pentadecane, tetradecane, and tridecane. Among the eight alkanes found in crude petroleum oil, tetradecane had the highest concentration at $10.39 \mathrm{ppb}$ and octane had the lowest concentration at $0.27 \mathrm{ppb}$ [24]. Four alkene compounds in crude petroleum oil were identified: 2-methyl-2,4-hexadiene, 2,6-octadiene, butadiene, and octadiene, the latter of which had the highest concentration (5.68 ppb). Two alkyne compounds, 3-heptyne and octyne, were found in crude petroleum oil. Remarkably, no alkane, alkene, or alkyne compounds were found in crude coconut oil. VOCs found in the crude coconut oil samples are listed in Table 3.

Four aromatic compounds were found in crude petroleum oil including benzene, naphthalene, toluene, and xylene. Toluene was the most abundant VOC in

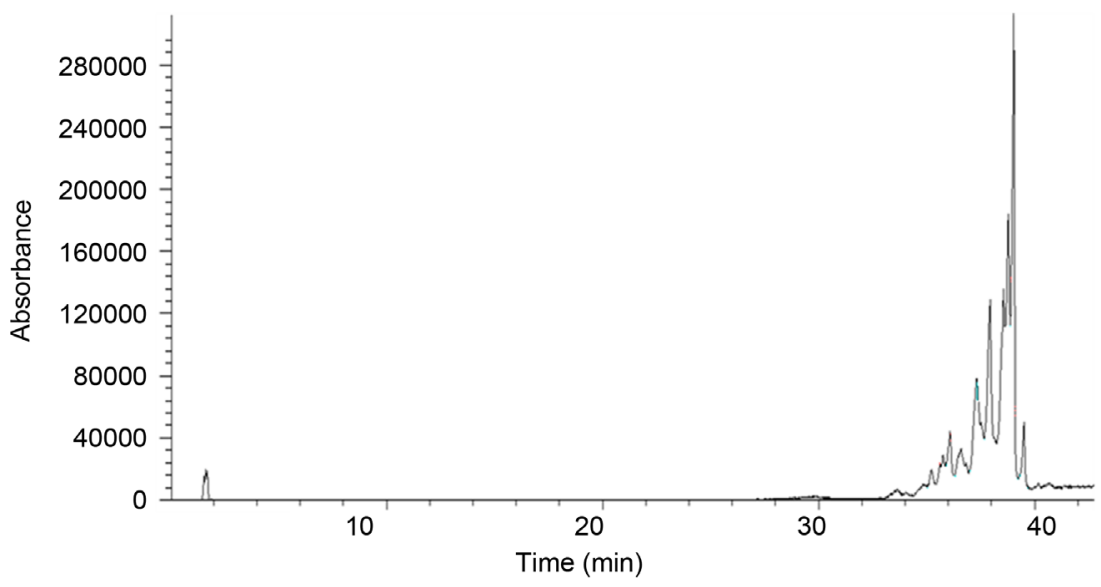

Figure 1. A representative gas chromatogram of crude coconut oil. 


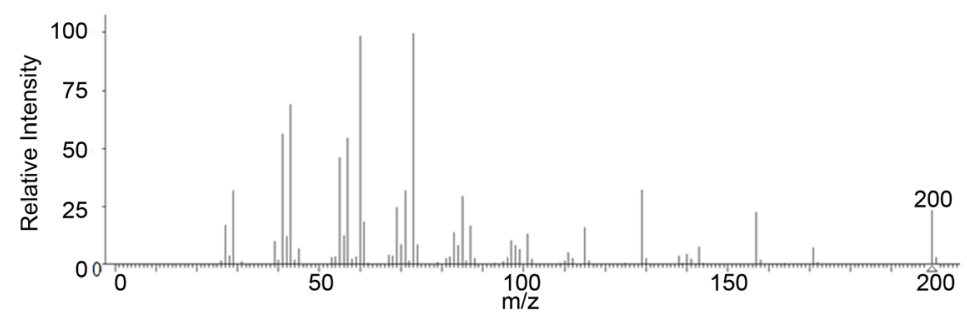

(a)

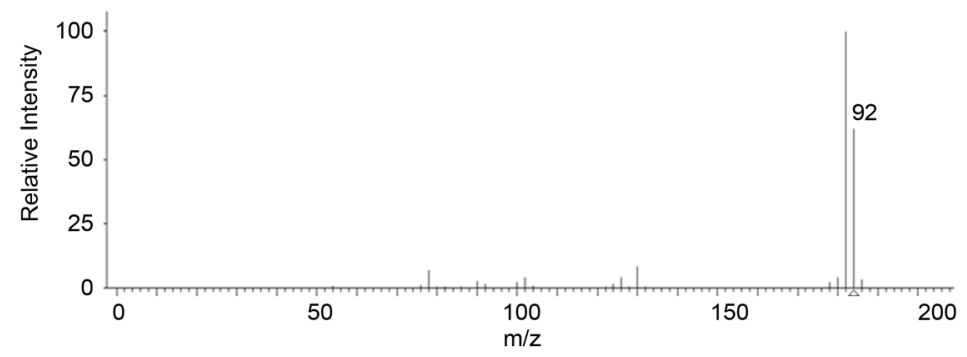

(b)

Figure 2. Mass spectra of the most abundant VOC of a) dodecanoic acid in crude coconut oil and b) toluene in crude petroleum oil.

crude petroleum oil at a concentration of $12.61 \mathrm{ppb}$; the mass spectrum of toluene is shown in Figure 2(b). Naphthalene was found at a concentration of 11.83 ppb in crude petroleum oil but was not present in crude coconut oil. Similar concentrations of benzene were found in crude coconut oil (2.68 ppb) and crude petroleum oil (3.68 ppb). Benzofuran was found in crude coconut oil (1.38 ppb) but was not detected in crude petroleum oil.

Two halogenated compounds (1-bromocyclooctene and dichloromethane) were found at low concentrations in crude petroleum oil, but none were detected in crude coconut oil. Three nitrogenated compounds, imidazole, indene-3ethanamine, and s-triazolo[4,3-a]pyridine, were only identified in crude petroleum oil. Conversely, butanamide and phenylserine were only found in crude coconut oil. One sulfurous compound, 2-ethylhexyl tetra-sulforous acid, was found in crude petroleum oil at a very small concentration $(0.20 \mathrm{ppb})$ but was not detected in coconut oil. Crude petroleum oil was found to have five oxygenated compounds, whereas crude coconut oil found to have four compounds. Cyclopentanol was the only one that was present in both crude oils. Hydromycrene, non-6-en-2-one, and thujone were found in crude petroleum oil. Dodecanoic acid was identified as the most abundant VOC in crude coconut oil (Figure 2(a)); carbamic acid and oxindole are other oxygenated compounds found in crude coconut oil.

Figure 3 shows the percentage of compounds by classification. For crude coconut oil (Figure 3(a)), oxygenated compounds account for $75 \%$ of the total VOCs, followed by aromatic compounds (20\%), and nitrogenated compounds (5\%). Figure 3(b) indicates that aromatic compounds comprise of $34 \%$ of the total VOCs in crude petroleum oil, followed by alkanes (32\%), alkynes (11\%), oxygenated compounds (10\%), alkenes (8\%), nitrogenated compounds (4\%), and halogenated compounds (1\%). The data from Figure 3 suggest that the 
Table 2. Concentrations (ppb) reported for VOCs found in crude petroleum oil ${ }^{*}$.

\begin{tabular}{|c|c|c|}
\hline Groups & Compounds & Concentration, $\mathrm{ppb}$ \\
\hline \multirow[t]{8}{*}{ Alkanes } & 2-Methylbicyclo[3.2.1] octane & 0.53 \\
\hline & 5-Ethyl-2,2,3-Trimethyl heptane & 0.37 \\
\hline & Decane & 7.51 \\
\hline & Dodecane & 5.44 \\
\hline & Octane & 0.27 \\
\hline & Pentadecane & 1.01 \\
\hline & Tetradecane & 10.39 \\
\hline & Tridecane & 1.58 \\
\hline \multirow[t]{4}{*}{ Alkenes } & 2-Methyl-2,4-Hexadiene & 0.02 \\
\hline & 2,6-Octadiene & 0.02 \\
\hline & Butadiene & 0.63 \\
\hline & Octadiene & 5.68 \\
\hline \multirow[t]{2}{*}{ Alkynes } & 3-Heptyne & 0.10 \\
\hline & Octyne & 9.55 \\
\hline \multirow[t]{4}{*}{ Aromatic } & Benzene & 3.68 \\
\hline & Naphthalene $e^{*}$ & 11.83 \\
\hline & Toluene & 12.61 \\
\hline & Xylene & 1.81 \\
\hline \multirow[t]{2}{*}{ Halogenated } & 1-Bromocyclooctene & 0.07 \\
\hline & Dichloromethane & 0.60 \\
\hline \multirow[t]{3}{*}{ Nitrogenated } & Imidazole & 0.72 \\
\hline & Indene-3-ethanamine & 2.00 \\
\hline & s-Triazolo $[4,3$-a]pyridine & 0.98 \\
\hline \multirow[t]{5}{*}{ Oxygenated } & Cyclopentanol & 0.53 \\
\hline & Hydromyrcene & 3.39 \\
\hline & Non-6-en-2-one & 1.11 \\
\hline & Thujone & 3.71 \\
\hline & Epoxyoctane & 0.94 \\
\hline Sulfurous & 2-ethylhexyl tetra-sulfurous acid & 0.20 \\
\hline
\end{tabular}

${ }^{\star}$ Each value is the average of three runs.

Table 3. Concentrations (ppb) reported for VOCs found in crude coconut oil ${ }^{\star}$.

\begin{tabular}{ccc}
\hline Groups & Compounds & Concentration, ppb \\
\hline Aromatic & Benzene & 2.68 \\
& Benzofuran & 1.38 \\
Nitrogenated & Butanamide & 0.68 \\
& Phenylserine & 0.35 \\
Oxygenated & Carbamic acid & 4.62 \\
& Cyclopentanol & 0.01 \\
& Dodecanoic acid & 9.98 \\
& Oxindole & 0.79 \\
\hline
\end{tabular}

${ }^{*}$ Each value is the average of three runs. 


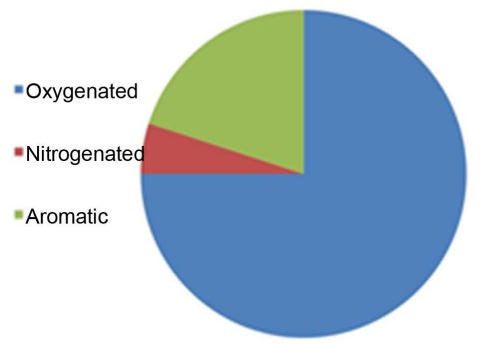

(a)

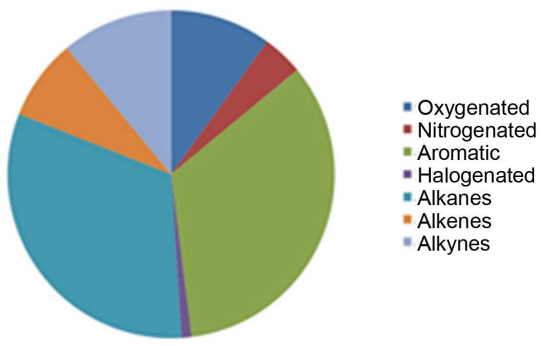

(b)

Figure 3. Comparison of VOCs measured by ppb found in crude coconut and petroleum oils. (a) Crude coconut oil; (b) Crude petroleum oil.

amount of nitrogenated-based VOCs in both oils are about the same level, whereas the level of oxygenated compounds in coconut oil is 7.5 times more than petroleum oil, though both contain different compounds. Total VOC concentrations were calculated as 87.46 and 20.49 ppb for crude petroleum oil and crude coconut oil, respectively.

\section{Conclusion}

Different VOCs were found in crude coconut and petroleum oils sourced from Ibadan, Nigeria. Twenty-nine VOCs were identified in crude petroleum oils, spanning eight chemical groups. Aromatic compounds and alkanes made up $66 \%$ of the total. Eight VOCs were identified in crude coconut oil; four oxygenated compounds accounted for $75 \%$ of the total VOCs. Remarkably, crude coconut oil contains no alkanes, alkenes, and alkynes. The total VOCs concentration of crude petroleum oil is about 4.3 times higher than crude coconut oil, suggesting that coconut oil is far more environmental-friendly than petroleum oil. Results obtained from this study reveal the types and amounts of VOCs found in crude coconut oil and petroleum oils, which serve as a framework for chemical signature for future forensics use or biofuel study.

\section{Acknowledgements}

Authors would like to thank H. L. Adebowale and E. O. Oyedokun of University of Ibadan, Nigeria for samples and ANA-Lab, Kilgore, TX for gas chromatography analysis.

\section{References}

[1] Fangrui, M. and Hanna, M. (1999) Biodiesel Production: Review. Bioresource Technology, 70, 1-15.

[2] Bozbas, K. (2008) Biodiesel as an Alternative Motor Fuel: Production and Policies in the European Union. Renew Sustainable Energy Reviews, 12, 542-552.

[3] Tan, R.R., Culaba, A.B. and Purvis, M.R.I. (2004) Carbon Balance Implication of Coconut Biodiesel Utilization in the Philippine Automotive Transport Sector. Biomass and Bioenergy, 26, 579-585.

[4] Padolina, W.G., Lucas, L.Z. and Torres, L.G. (1987) Chemical and Physical Properties of Coconut Oil. Philippine Journal of Coconut Studies, XII, 4-17. 
[5] Erhan, S.Z. and Asadaukas, S. (2000) Lubricant Base Stockes from Vegetable Oils. Industrial Crops and Products, 11, 277-282.

[6] Machacon, H.T.C., Matsumoto, Y., Ohkawara, C., Shiga, S., Karasawa, T. and Nakamura, H. (2001) The Effect of Coconut Oil and Diesel Fuel Blends on Diesel Engine Performance and Exhaust Emissions. JSAE Review, 22, 349-355.

[7] Kalam, M.A., Husnawan, M. and Masjuki, H.H. (2003) Exhaust Emission and Combustion Evaluation of Coconut Oil Powered Indirect Injection Diesel Engine. Renewable Energy, 28, 2405-2415.

[8] Santos, J.E.R., Villarino, B.J., Zosa, A.R. and Dayrit, F.M. (2011) Analysis of Volatile Organic Compounds in Virgin Coconut Oil and Their Sensory Attributes. Philippine Journal of Science, 140, 161-171.

[9] Tvedt, J. (2002) The Effect of Uncertainty and Aggregate Investments on Crude Oil Price Dynamics. Journal of Energy Economics, 24, 615-628.

[10] World Resources Institute (1999) Rising Energy Use: Health Effects of Air Pollution. www.wri.org

[11] World Health Organization (2000) Air Pollution: WHO's 1999 Guidelines for Air Pollution Control. Fact Sheet No. 187.

http://www.who.int/mediacentre/factsheets/fs187/en/

[12] United States Environmental Protection Agency. Health and Environmental Effects Profile for Naphthalene (1986).

https://cfpub.epa.gov/ncea/iris_drafts/recordisplay.cfm?deid=49301

[13] CARB (1998) Proposed Identification of Diesel Exhaust as a Toxic Air Contaminants. Part A: Exposure Assessment. California Air Resources Board, 103.

[14] Shales, S., Thake, B.A., Frankland, B., Khan, D.H., Hutchinson, J.D. and Mason, C.F. (1989) Biological and Ecological Effects of Oils. In: Green, J. and Treett, M., Eds., The Fate and Effects of Oil in Freshwater, British Petroleum and Elsevier Applied Science, London, NY, 81-106. https://doi.org/10.1007/978-94-009-1109-3_4

[15] Tucker, W.G. (2001) Volatile Organic Compounds (VOCS). Indoor Air Quality Handbook. McGraw-Hill Companies, New York, 1-31.

[16] Golfinopoulos, S.K., Lekkas, T.D. and Nikolaou, A.D. (2000) Comparison of Methods for Determination of Volatile Organic Compounds in Drinking Water. Chemosphere, 41, 1149-1154.

[17] Wang, Z. and Fingas, M. (1997) Developments in the Analysis of Petroleum Hydrocarbons in Oils, Petroleum Products and Oil-Spilled-Related Environmental Samples by Gas Chromatography. Journal of Chromatography A, 774, 51-78. https://doi.org/10.1016/S0021-9673(97)00270-7

[18] Tamaddoni, M., Sotudeh-Gharebagh, R., Nario, S., Hajihosseinzadeh, M. and Mostoufi, N. (2014) Experimental Study of VOC Emitted from Crude Oil Tankers. Process Safety and Environmental Protection, 92, 929-937. https://doi.org/10.1016/j.psep.2013.10.005

[19] Wei, W., Cheng, S., Li, G., Wang, G. and Wang, H. (2014) Characteristics of Volatile Organic Compounds (VOCs) Emitted from a Petroleum Refinery in Beijing, China. Atmospheric Environment, 89, 358-366. https://doi.org/10.1016/j.atmosenv.2014.01.038

[20] Ayoka, G.A., Singh, A., Lim, M.C.H., Ristosvski, Z.D., Jayaratne, E.R., Morawska, L., King, G. and Christensen, E. (2014) Characterization of VOCs from LPG and Unleaded Petroleum Fuelled Passenger Cars. Fuel, 115, 636-643. https://doi.org/10.1016/j.fuel.2013.06.031

[21] Dinh, T.V., Choi, I.Y., Son, Y.S., Song, K.Y., Sunwoo, Y. and Kim, J.C. (2015) Vola- 
tile Organic Compounds (VOCs) in Surface Coating Materials: Their Compositions and Potential as an Alternative Fuel. Journal of Environmental Management, 168, 157-164. https://doi.org/10.1016/j.jenvman.2015.11.059

[22] Wei, W., Lv, Z., Yang, G., Cheng, S., Li, Y. and Wang, L. (2016) VOCs Emission Rate Estimate for Complicated Industrial Area Source Using an Inverse-Dispersion Calculation Method: A Case Study on a Petroleum Refinery in Northern China. Environmental Pollution, 218, 681-688. https://doi.org/10.1016/j.envpol.2016.07.062

[23] Lee, M.L., Yang, F.J. and Bartle, K.D. (1984) Open Tubular Column Gas Chromatography: Theory and Practice. John Wiley and Sons, Inc., New York, 225-226.

[24] Monteiro-Riviere, N.A., Inman, A.O. and Riviere, J.E. (2004) Skin Toxicity of Jet Fuels: Ultrastructural Studies and the Effects of Substance P. Toxicology and Applied Pharmacology, 195, 339-347. https://doi.org/10.1016/j.taap.2003.07.013

\section{Submit or recommend next manuscript to SCIRP and we will provide best service for you:}

Accepting pre-submission inquiries through Email, Facebook, LinkedIn, Twitter, etc. A wide selection of journals (inclusive of 9 subjects, more than 200 journals) Providing 24-hour high-quality service User-friendly online submission system Fair and swift peer-review system Efficient typesetting and proofreading procedure Display of the result of downloads and visits, as well as the number of cited articles Maximum dissemination of your research work

Submit your manuscript at: http://papersubmission.scirp.org/

Or contact ajac@scirp.org 